Western University

Scholarship@Western

Human Environments Analysis Lab (HEAL)

2019

The Impact of Canadian School Food Programs on Children's

Nutrition and Health: A Systematic Review

Paige Colley

Western University

Bronia Myer

Western University

Jamie A. Seabrook

Brescia University, jseabro2@uwo.ca

Jason A. Gilliland

Western University, jgillila@uwo.ca

Follow this and additional works at: https://ir.lib.uwo.ca/healpub

Citation of this paper:

Colley, Paige; Myer, Bronia; Seabrook, Jamie A.; and Gilliland, Jason A., "The Impact of Canadian School Food Programs on Children's Nutrition and Health: A Systematic Review" (2019). Human Environments Analysis Lab (HEAL). 27.

https://ir.lib.uwo.ca/healpub/27 


\section{The Impact of Canadian School Food Programs on Children's Nutrition and Health: A Systematic Review}

\section{PAIGE COLLEY, MSc ${ }^{a}$; BRONIA MYER ${ }^{b}$; JAMIE SEABROOK, PhD ${ }^{c, d}$; JASON GILLILAND, PhD}

${ }^{a}$ Health and Rehabilitation Sciences, Western University, London, ON; ${ }^{b}$ Medical Sciences and Psychology, Western University, London, ON; 'School of Food and Nutritional Sciences, Brescia University College at Western University, London, ON; ${ }^{\mathrm{d} D e p a r t m e n t ~ o f ~ P a e d i a t r i c s ~ a n d ~ E p i d e m i o l o g y ~ \& ~ B i o s t a t i s t i c s, ~}$ Western University, London, ON; ${ }^{e}$ Department of Geography, Health Studies, Paediatrics, and Epidemiology \& Biostatistics, Western University, London, ON

\begin{abstract}
The quality of children's diets has declined over the past few decades, giving rise to a variety of health-related consequences. In response to this trend, school food programs have become an increasingly effective method to support nutrition and lifelong healthy eating habits. This systematic review synthesizes current academic literature pertaining to school nutrition programs in Canada to identify existing interventions and their impacts on children's nutritional knowledge, dietary behaviour, and food intake. The review was conducted through a search of the following databases: ERIC, Education Source, CINAHL, PubMed, SagePub, SCOPUS, EMBASE, and CBCA. Information extracted from the articles included the program objectives, intervention design and components, research evaluation, and primary outcomes. A total of 11 articles evaluating Canadian school nutrition programs were identified. The programs incorporated a variety of intervention components including policy, education, family and community involvement, and/or food provision. These multi-component interventions were positively associated with children's development of nutrition knowledge, dietary behaviour changes, and intake of healthy foods; however, barriers associated with intervention duration, intensity, and availability of resources may have influenced the extent to which these programs impacted children's diets and overal health.
\end{abstract}

(Can J Diet Pract Res. 2019;80:79-86)

(DOI: 10.3148/cjdpr-2018-037)

Published at dcjournal.ca on 15 November 2018

\section{RÉSUMÉ}

La qualité de l'alimentation des enfants s'est détériorée au cours des dernières décennies, causant l'augmentation d'une variété de conséquences sur la santé. En guise de réponse à cette tendance, les programmes d'alimentation dans les écoles constituent désormais des méthodes de plus en plus efficaces pour favoriser un apport nutritionnel adéquat et créer de saines habitudes alimentaires qui dureront toute la vie. Cette revue systématique résume les recherches universitaires actuelles menées sur les programmes d'alimentation dans les écoles du Canada afin de relever les interventions existantes et leurs effets sur les connaissances nutritionnelles, les comportements alimentaires et l'apport alimentaire des enfants. La revue a été réalisée grâce à des recherches effectuées dans les bases de données suivantes: ERIC, Education Source, CINAHL, PubMed, SagePub, SCOPUS, EMBASE et CBCA. L'information tirée des articles comprend les objectifs des programmes, la méthodologie et les composantes des interventions, l'évaluation de la recherche et les objectifs principaux. Un total de 11 articles évaluant les programmes d'alimentation dans les écoles du Canada ont été trouvés. Les programmes intégraient une variété d'éléments d'intervention tels que des politiques, de l'éducation, l'implication des familles et de la collectivité, et des mesures en matière d'offre alimentaire. Ces interventions à composantes multiples étaient positivement associées au développement des connaissances nutritionnelles, à des changements de comportement alimentaire et à un apport en aliments sains chez les enfants. Cependant, des obstacles associés à la durée et à l'intensité de l'intervention et à la disponibilité des ressources peuvent avoir influencé la portée de l'effet de ces programmes sur l'alimentation des enfants et sur leur santé globale.

(Rev can prat rech diétét. 2019;80:79-86)

(DOI: 10.3148/cjdpr-2018-037)

Publié au dcjournal.ca le 15 novembre 2018

\section{INTRODUCTION}

Concerns about the quality of children's diets have received considerable attention in recent decades. Many children are consuming foods of low-nutritional value, leading to dietary excesses and nutritional inadequacies [1]. Only $10 \%$ of Canadian youth are meeting the Canada's Food Guide recommended intake of fruit and vegetable (F/V) servings [2]. Similar trends can be found across many food groups, with few children meeting basic nutrition standards [3].

Children with poor diets are prone to immediate and longterm health consequences [4]. Nearly one-third of Canadian children are overweight or obese [5], which increases the risk of developing type 2 diabetes, heart disease, and some forms of cancer [6-8]. Inadequate nutrition can also impact brain development, leading to a variety of psychosocial and behavioural problems [9-11]. It is therefore important to identify effective nutrition interventions that promote healthy eating and reduce the risk of debilitating health problems.

School food programs offer a promising method to support child nutrition and lifelong healthy eating habits. Students participating in school food programs demonstrate increased nutritional knowledge, preferences for healthy foods, and a higher intake of nutrient-dense foods [12, 13]. With increased access to healthy foods, children are less likely to consume non-nutritious foods [14]. Improved dietary behaviours can offset risk for health-related problems associated with poor eating patterns and nutritional deficiencies $[15,16]$. 
Canada is the only nation among the G8 (i.e., the group of 8 highly industrialized nations, including France, Germany, Italy, Japan, Russia, the United Kingdom, and the United States), without a national school food program. In the absence of such a program, there are many regional and provincial food programs with different funding systems, intervention components, and delivery methods that vary greatly by region and school. A review of current research on school food programs is warranted to identify best practices and set a strong foundation for establishing a national program. Although reviews of school food programs in other countries exist, these programs may be context-driven and not necessarily replicable and transferable. Thus, an opportunity exists to examine school nutrition programming in Canada.

This systematic review synthesizes academic research on Canadian school nutrition programs by identifying existing interventions and their impacts on children's nutrition. The PICO (Patient, Intervention, Comparison and Outcome) model [17] was applied to formulate and address the proposed research question: "How do Canadian elementary school nutrition programs impact children's nutritional knowledge, dietary behaviour, and/or food intake?" Nutritional knowledge is broadly defined as concepts and processes relating to nutrition and health, including information about healthy eating, diet and disease prevention, nutritional value of foods, and awareness of dietary guidelines [18]. Dietary behaviours are often shaped by personal, familial, social, and physical environmental factors [19]. This review will identify dietary behaviour changes regarding food preferences, willingness to try new foods, self-efficacy, attitudes, and perceptions of healthy eating. Finally, direct measurements of food intake will be assessed, highlighting ways in which school nutrition programs influence children's consumption patterns. The search aims to investigate elementary schools to better understand the influence of nutrition programming at an age when lifelong eating behaviours are being formed. A narrative description of the results will be conducted to incorporate the varied qualitative and quantitative study designs.

\section{METHODS}

This systematic review documented peer-reviewed literature focused school food programs in Canada and synthesized children's health outcomes. The search was limited to academic studies published after 1990, in accordance with the first school nutrition policy [20]. The search used in this review is current as of March 2017. In consultation with university librarians and academic experts in the field, 4 main concepts were developed to create a consistent and comprehensive search strategy: "geographical location" to identify Canadian articles, "program type" to reflect the specific nature of the interventions, "setting" to keep the scope of interventions within a school environment, and "initiative" to filter results away from policies, guidelines, and theoretical strategies.

The search strategy outlined in Supplementary Figure $1^{1}$ was applied to 8 databases including: ERIC, Education Source, CINAHL, PubMed, SagePub, SCOPUS, EMBASE, and CBCA Education. Two reviewers independently assessed the inclusion and exclusion of peer-reviewed articles using the PICO search strategy [17]. All papers were required to meet the following criteria: ( $i$ ) conducted in Canada, (ii) evaluated programs based in elementary schools, (iii) contained a program that offers food provision during the school day, (iv) contained a primary evaluation, assessment, or analysis of the program, and $(v)$ reported a primary outcome that is related to children's health (e.g., nutritional knowledge, dietary behaviours). Conversely, articles were excluded if they assessed a legislative policy or school strategy (e.g., a toolkit or guideline) rather than an actual food program. Any articles that were a summary of a program, did not contain a primary analysis, or failed to report a primary outcome were excluded. The reference lists of the included articles were also screened for additional studies.

The systematic review process followed PRISMA (Preferred Reporting Items for Systematic Reviews and Meta-Analyses) guidelines illustrated in Figure 1 [21]. After the articles were identified, data extraction included article reference, objectives, population, intervention design and components, research evaluation, and main outcomes (see Supplementary Table $1^{1}$ ). Considering the varied study designs, we elected to use the Integrated Quality Criteria for the Review of Multiple Study designs (ICROMS) to assess paper quality (see Supplementary Table $2^{1}$ ). ICROMS facilitates the critical appraisal of behavioural change intervention studies in the field of health [22]. It incorporates the assessment of multiple designs including randomized, controlled pre- and post-, interrupted time series, noncontrolled, cohort, and qualitative studies. For studies with cross-sectional designs not included in ICROMS, internal validity was evaluated using Strengthening the Reporting of Observational Studies in Epidemiology (see Supplementary Table $3^{1}$ ) [22].

Using ICROMS [22], a study was given 2 points if the criteria were met, 0 points if they were not met, and 1 point for unclear assessment of criteria. The sum of the quality criterion was then totalled for each study to provide an overall quality score. A total score $<60 \%$ was labelled high risk of bias or low reliability. Total scores between $60 \%$ and $80 \%$ were labelled medium risk of bias or medium reliability. Studies with total scores $>80 \%$ were recorded as low risk of bias or high reliability. For studies included in STROBE (Strengthening The Reporting of Observational Studies in Epidemiology), a checklist of items was used to assess the quality of reporting. To capture all literature relevant to this review, we did not exclude studies based on the quality of evidence or reporting provided. Two authors independently assessed the methodological quality of each of the 11 articles and obtained a high correlation between the assessments.

${ }^{1}$ Supplementary data are available with the article through the journal Web site at https://dcjournal.ca/doi/suppl/10.3148/cjdpr-2018-037. 
Figure 1. Systematic review data extraction table. Articles were primarily excluded because they did not include an evaluation of a food program/intervention $(n=22)$. Several programs did not offer food provision $(n=12)$. In addition, some interventions focused on other age groups $(n=5)$, settings $(n=6)$, or times $(n=6)$. Many articles were excluded because relevant health outcomes pertaining to children's dietary behaviours, food intake, or knowledge were not reported $(n=14)$. A few articles were excluded because they were not Canadian $(n=5)$ or were conducted prior to $1990(n=1)$.

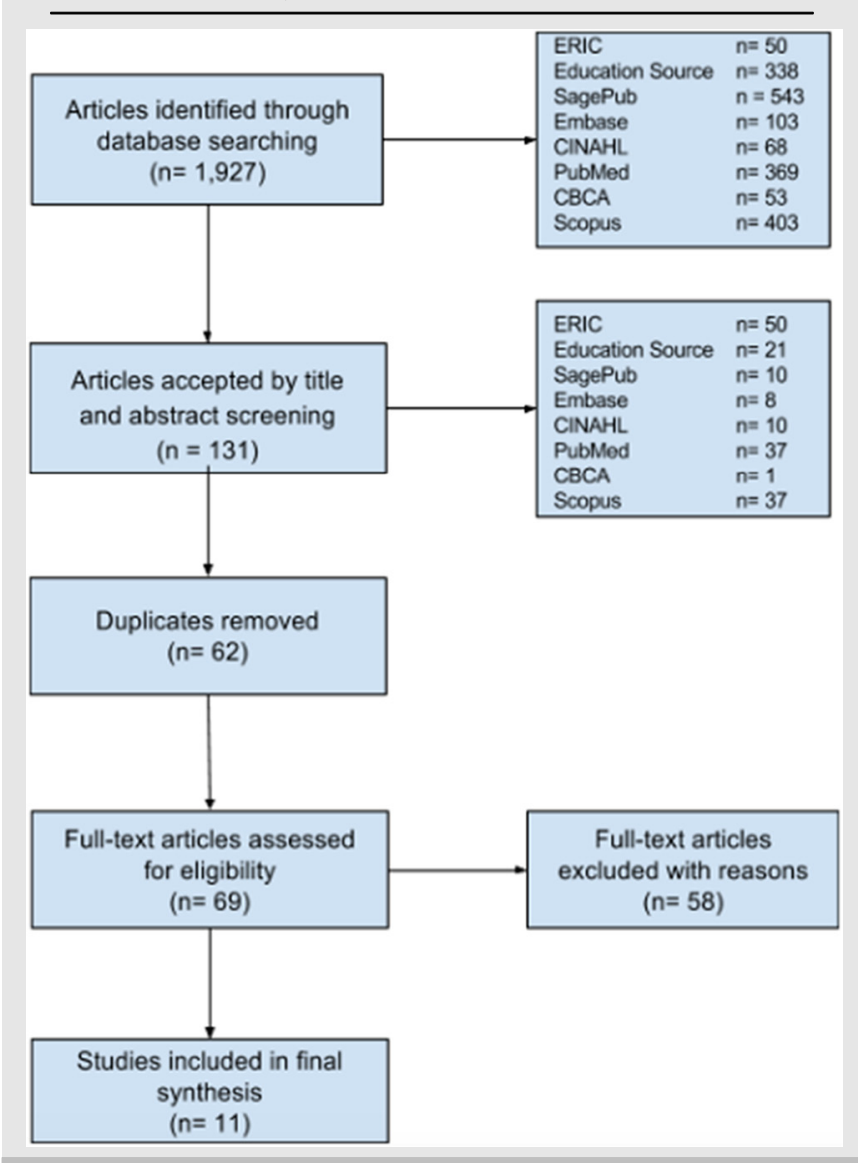

\section{RESULTS}

The search strategy resulted in the retrieval of 11 articles, reporting results from 9 school-based nutrition programs (see Table 1). The school food programs were dispersed across Canada, with interventions in British Columbia $(\mathrm{n}=1)$, Alberta $(n=2)$, Ontario $(n=4)$, Quebec $(n=1)$, and Nova Scotia $(n=1)$. Of the 9 programs identified, 4 interventions were offered in Indigenous communities, with the remaining 5 programs in both rural and urban elementary school settings. Program interventions often targeted disadvantaged or remote populations prone to food insecurity and nutrition deficiencies.
The selected articles included a variety of quantitative $(\mathrm{n}=8)$, qualitative $(\mathrm{n}=1)$, and mixed-methods $(\mathrm{n}=2)$ studies. Eight articles included a pre- and post-intervention evaluation, and 4 studies utilized a control group. The number of child participants ranged from small-scale initiatives (min., $\mathrm{n}=30$ ) within a single school-based location to large-scale initiatives (max., $\mathrm{n}=5200)$ that were province-wide $(\mathrm{n}=282$ schools). Of the studies assessed using ICROMS, all were found to be medium to low risk of bias (see Supplementary Table $2^{1}$ ). Studies appraised using STROBE indicated a high adherence to quality criterion recommendations (see Supplementary Table $3^{1}$ ).

\section{Intervention components}

Intervention designs and components varied according to program objectives, populations, and settings. Most studies included multi-component interventions $(\mathrm{n}=8)$, with 1 program offering only food provision. Recurring intervention components included implementation of policy, education, food provision, and/or family, peer and community involvement. Through multi-component designs, some programs $(\mathrm{n}=5)$ incorporated healthy eating and nutrition policies $[23,24]$ and prohibited consumption of low-nutrient quality foods [25]. Most of the school interventions incorporated an education component $(n=8)$, which varied in intensity and duration. Passive educational methods included classroom activities and materials to promote healthy eating, information letters, messages in school newsletters and announcements, classroom discussions, and healthy meal planning. Some programs offered intensive educational approaches with regularly scheduled nutrition classes, classroom activities, cooking clubs, peer modeling, and health curriculum. A few programs $(n=5)$ also implemented education tied to the curriculum, one of which included a full-time school health facilitator to organize education programs and promote healthy eating [12]. All interventions $(n=9)$ incorporated food provision; however, this varied in quantity from taste-testing activities to daily administration of healthy snacks or meals. Parent, teacher, and community involvement included handouts, newsletters, presentations, classroom activities, take-home resources, workshops, and community feasts.

\section{Impact on nutritional knowledge, dietary behaviours, and/or food intake}

Several studies evaluated the impact of school food programs on children's nutritional knowledge, dietary behaviours, and/ or food intake. Of the included articles, 6 interventions evaluated changes in children's nutritional knowledge. The results indicated increases in children's nutritional knowledge $(\mathrm{n}=4)$. Participants displayed improvement in dietary and health curriculum knowledge [25], specifically demonstrating a greater understanding of nutritional contents of foods, food transformation, and cooking procedures [26]. A few studies found increased knowledge of select food groups, including 
Table 1. Summary of school nutrition program studies.

\begin{tabular}{|c|c|c|c|}
\hline Program reference & Population & Intervention components & Reported outcomes \\
\hline Gates et al. 2013 [23] & $\begin{array}{l}\text { Children grades } 6-8(\mathrm{n}=10, \\
\text { Web-Q survey) and }(\mathrm{n}=19, \\
\mathrm{KSIQ} \text { survey) in } 1 \text { school in Fort } \\
\text { Albany, Ontario }\end{array}$ & $\begin{array}{l}\text { Policy; education; food } \\
\text { provision; and family, peer, } \\
\text { and community involvement } \\
\text { (1 y) }\end{array}$ & $\begin{array}{l}\text { - Significant improvement in knowledge and intentions } \\
\text { regarding MMA intake } \\
\text { - Insufficient intake of recommended servings of MMA }\end{array}$ \\
\hline Day et al. 2008 [28] & $\begin{array}{l}\text { Children in grades } 4 \text { and } 5 \\
(\mathrm{n}=444) \text { in } 10 \text { schools in } \\
\text { British Columbia }\end{array}$ & $\begin{array}{l}\text { Policy, education, food provision, } \\
\text { and family and community } \\
\text { involvement (12 weeks) }\end{array}$ & $\begin{array}{l}\text { - Increase in } \mathrm{F} \text { consumption, variety of F/V, and F/V tried } \\
\text { - No effects were found for typical daily F/V consumption; } \\
\text { servings of } \mathrm{V} \text {; willingness to try; knowledge, attitudes, and } \\
\text { perceptions }\end{array}$ \\
\hline Triador et al. 2015 [29] & $\begin{array}{l}\text { Children grades } 1-6(n=76) \text { at } \\
1 \text { school in Alexander, Alberta }\end{array}$ & $\begin{array}{l}\text { Education, food provision, and } \\
\text { family and community } \\
\text { involvement (11 mo) }\end{array}$ & $\begin{array}{l}\text { - An increase in F/V preference } \\
\text { - Self-reported consumption of F/V at home did not change }\end{array}$ \\
\hline Hanbazaza et al. 2015 [27] $]^{a}$ & $\begin{array}{l}\text { Children grades } 1-6(n=66) \text { at } \\
1 \text { school in Alexander, Alberta }\end{array}$ & $\begin{array}{l}\text { Education, food provision and } \\
\text { family and community } \\
\text { involvement (18 mo) }\end{array}$ & $\begin{array}{l}\text { - Increased knowledge about F/V } \\
\text { - Improvement in short-term V preferences and long-term F } \\
\text { preferences } \\
\text { - No change in F/V consumption at home }\end{array}$ \\
\hline Bisset et al. 2008 [26] & $\begin{array}{l}\text { Children grades } 5 \text { and } 6 \\
(\mathrm{n}=388) \text {, at } 7 \text { schools in } \\
\text { Montreal, Quebec }\end{array}$ & $\begin{array}{l}\text { Education, food provision, and } \\
\text { family and community } \\
\text { involvement }(7 \mathrm{y})\end{array}$ & $\begin{array}{l}\text { - Greater knowledge of nutrition content, preparation, and } \\
\text { cooking procedures } \\
\text { - No difference in knowledge of Canada's Food Guide, local } \\
\text { produce, or international cuisine } \\
\text { - Increased attitudes and experience with trying new or less- } \\
\text { common foods }\end{array}$ \\
\hline He et al. 2009 [13] ${ }^{b}$ & $\begin{array}{l}\text { Children grades } 5-8(n=1277) \\
\text { from } 26 \text { schools across } 7 \\
\text { Northern Ontario communities }\end{array}$ & $\begin{array}{l}\text { Education and food provision } \\
\text { (21 weeks) }\end{array}$ & $\begin{array}{l}\text { - Higher F/V intake and preferences } \\
\text { - Moderate levels of self-efficacy and habits } \\
\text { - Change in preference scores from never tried to like } \\
\text { - Intervention II had unfavourable changes in self-efficacy and } \\
\text { consumption of } \mathrm{V} \\
\text { - Combined education component was more effective }\end{array}$ \\
\hline
\end{tabular}




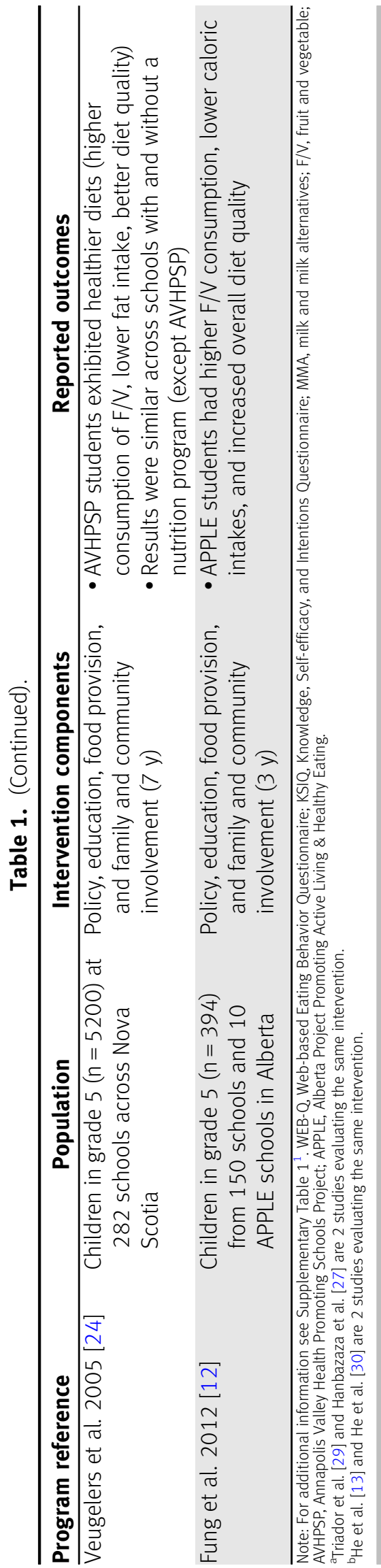

milk and alternatives $(\mathrm{M} / \mathrm{A})$, and $\mathrm{F} / \mathrm{V}[23,27]$. On the other hand, 3 studies reported no differences in knowledge following the intervention, including no significant changes in $\mathrm{F} / \mathrm{V}$ knowledge [28] and similar levels of knowledge regarding daily F/V intake between intervention and control groups [13]. Although Bisset et al. [26] reported increases in children's food knowledge, there were no differences in knowledge pertaining to Canada's Food Guide, local produce, or international cuisine. The findings also indicated that intervention duration of a year or more was positively associated with increases in children's nutritional knowledge.

Several studies $(n=7)$ evaluated the impact of school nutrition programs on children's food preferences, willingness to try, self-efficacy, intentions, attitudes, and perceptions of healthy eating. Of these studies, all program interventions had a positive influence on children's dietary behaviours. Not only did participants indicate an increased preference for high-nutrient dense foods, such as F/V [27, 29], but their attitudes and willingness to try a variety of new foods, particularly $\mathrm{F} / \mathrm{V}$, also increased $[13,26]$. One study reported a shift in children's preference from never having tried to liking food items [13]. More broadly, a few articles described a significant positive change in children's dietary self-efficacy [25], intentions [23], and perceptions [30]. However, the longevity and extendibility of dietary behaviour change may be limited to the intervention context. For example, Hanbazaza et al. [27] noted a decline in vegetable preferences from 7 to 18 months' post-intervention, while Day et al. [28] found no effects in relation to daily willingness to try, attitudes, and perceptions of $\mathrm{F} / \mathrm{V}$ consumption.

Food consumption patterns and intake measurements were obtained across most of the program interventions $(\mathrm{n}=8)$. Among the studies evaluating food intake, over half of the programs $(n=6)$ reported increased consumption of healthy foods, including a higher intake of $\mathrm{F} / \mathrm{V}[12,13,28]$ and M/A [31]. Significant changes in micronutrient consumption, with increases in fibre [25], calcium, and vitamin D were also reported [31]. Overall, participants exhibited lower caloric intake and increased diet quality $[12,24]$. However, some studies $(n=3)$ reported no significant changes in intake and insufficient consumption of vegetables [28] and M/A [23], particularly within daily consumption and over extended periods of time. Conflicting findings relating to food intake patterns at home were also reported, with 1 study noting higher consumption of F/V [30] and another study reporting no food intake changes [29].

\section{DISCUSSION}

Nearly all of the studies investigated programs with multicomponents, including a combined use of policy, education, family and community involvement, and/or food provision, which were found to be effective. To this point, Veugelers et al. [24] emphasized the value of integrative approaches that incorporate intensive and multifaceted components, to support child nutrition and lifelong healthy eating habits. 
Likewise, Gates et al. [31] evaluated the impact of a program offering food provision only, and discussed the benefits of extending the evaluation and integrating other elements to enhance the program. Interventions that were effective in changing dietary behaviour were ones that employed a comprehensive approach $[23,32]$. The significance of these outcomes could be further improved if intervention components were tailored to school and community needs [23]. Interventions may benefit from high exposure involving community leadership, school nutrition policies, parental engagement, and cultural adaptations relevant to the population $[23,25]$.

Examining the interventions for effects on children's nutritional knowledge, dietary behaviour, and/or food intake revealed positive outcomes. Several studies reported increased nutritional knowledge associated with interventions, noting outcomes pertaining to dietary and health curriculum knowledge, nutritional contents of food, food preparation, and cooking procedures $[23,25-27]$. These findings are similar to existing literature, highlighting the benefits of school nutrition programs in increasing children's nutritional knowledge [33]. Moreover, school-based interventions that include an education component supplementary to the curriculum (i.e., nutrition classes, cooking clubs, and healthy eating resources) can be particularly effective in enhancing children's nutritional knowledge [23, 25, 34].

Outcomes related to intervention impacts on children's dietary behaviours were considerable. Specific results included increased preference for high-nutrient foods, positive attitudes and willingness to try new foods, enhanced likability, shifts in dietary self-efficacy, and improved eating habits [26, 27, 29, 30]. These dietary changes may be attributed to a variety of program components. Increased access to healthy food through provisional practices was found to influence food preferences and liking new foods $[13,23,29]$, and F/V tasting activities were a highly effective method for enhancing food preferences $[13,28,29]$. Increased preferences are associated with long-term dietary behaviour changes into adulthood [29]. Additionally, interventions documented community and familial behavioural changes. Gates et al. [31] discussed community changes, including stocking grocery stores with similar food accessed through the program. Parents also displayed changes in purchasing behaviours by buying healthier food [25]. With increased access and promotion of healthier food options among parents, these changes can ultimately influence children's food preferences and dietary behaviours $[13,27]$. A combination of personal and environmental factors associated with the intervention, such as knowledge of healthy foods and food provision, were discussed as being primary factors for increases in children's food preferences [29].

Children's increased consumption of healthy foods was another positive outcome resulting from the school food interventions. In 2 studies, participants demonstrated higher intake of $\mathrm{F} / \mathrm{V}, \mathrm{M} / \mathrm{A}$, and micronutrients and better overall diet quality $[25,31]$. Offering daily sources of $F / V$ was associated with increased dietary intake and offsets nutritional deficiencies leading to health risks and disease [25,27]. This finding coincides with research reporting distribution of $\mathrm{F} / \mathrm{V}$ as a practical strategy to increase children's intake [35]. Food provision in partnership with education demonstrated favourable intervention effects on F/V consumption [13].

Although the studies reviewed presented many ways in which school food programs impacted children's nutrition, recurrent barriers and challenges may have influenced the extent to which the programs were effective. Barriers concerning intervention duration, intensity, and availability of resources were frequently discussed within the articles. Some studies discussed challenges pertaining to intervention length and inhibited outcomes of dietary behavioural changes [29, 31]. Gates et al. [23] acknowledged that the intervention education component (2.5 hours) was insufficient to invoke dietary behaviour changes. It was recommended to increase intervention duration to 1 year or more to produce significant effects and sustainable change $[28,36]$.

Many studies discussed the low intensity of intervention methods as a frequent barrier to influencing children's nutritional knowledge acquisition and consumption patterns $[13,23]$. The delivery method of some programs was regularly inconsistent and sporadic, often due to limited capacity to deliver produce in remote regions or lack of support [13]. Providing consistent program provision is suggested to enhance operation and implementation [28]. Within both food provision and education components, studies reported a lack of repetition which is necessary for behaviour changes and knowledge acquisition [26]. Reiteration of nutritional topics and information, and repeat exposure to healthy food items is recommended to invoke dietary change $[26,28]$. In relation to intervention parent and community components, parental involvement was often limited and passive [13,23]. Active parental and community involvement may be an effective method to model healthy eating behaviours and promote consumption of nutritious foods [23].

Financial and human support were mentioned as a recurring challenge amongst program interventions [28, 31]. Studies reported a lack of available and affordable nutritious food at school and home, impacting program sustainability and dietary behavioural outcomes [23, 27, 29]. Furthermore, barriers related to staffing, equipment, resources, and other logistical components were acknowledged as constraints to implementation $[28,31]$. In response to these barriers, it was recommended to increase human support, resources, and access to affordable healthy food items $[28,29]$. Although the studies presented a variety of intervention barriers, the proposed solutions offer practical strategies to enhance the reported impact of the school-nutrition programs discussed within this review.

\section{Limitations}

This review is not without limitations. Specific terms, such as gardening and cooking, were not included within the search 
strategy of this review. Including these types of programs in the search protocol could have contributed to the findings in this review. This review only focused on school food programming in elementary schools. The findings may not be reflective of other age groups and settings. Based on the ethnic composition of Canada, results were drawn from several studies focused on Indigenous communities, which are not representative of the general population. This is attributed to the limited number of Canadian studies evaluating school nutrition programs and the propensity of programs to target disadvantaged communities. Finally, this review focused on peerreviewed literature. There may be evaluations of school food programming existing within the grey literature.

\section{RELEVANCE TO PRACTICE}

The multi-component school nutrition programs identified in this systematic review positively influenced children's nutritional knowledge, dietary behaviours, and food intake. The search also identified, however, that implementation barriers associated with time, intensity, and resources limited program effectiveness. Dietitians and school nutrition programming stakeholders are encouraged to establish universal implementation guidelines to support efficient and effective program delivery [37]. These guidelines may include recommendations on adopting a school nutrition policy, providing comprehensive nutrition education, integrating parental and community involvement, and implementing food services. Supplementing these guidelines, additional research using rigorous experimental study designs with pre- and post-evaluations is warranted to investigate the success of these strategies in practice. Current research findings will aid in establishing an effective and sustainable nationwide school food program.

Financial support: PC received graduate trainee support from the Children's Health Research Institute through funding from the Children's Health Foundation. No other funding or financial support.

Conflict of interest: The authors declare that they have no competing interests.

\section{References}

1. Taylor JP, Evers S, McKenna M. Determinants of healthy eating in children and youth. Can J Public Health. 2005 Jul-Aug;96:S20-6. PMID: 16042160. doi: 10.17269/cjph.96.1501.

2. Minaker L, Hammond D. Low frequency of fruit and vegetable consumption among Canadian youth: findings from the 2012/2013 Youth Smoking Survey. J Sch Health. 2016 Feb;86(2):135-42. PMID: 26762825. doi: 10.1111/ josh.12359.

3. Garriguet D. Overview of Canadians' eating habits. Ottawa, ON: Statistics Canada; 2006. $47 \mathrm{p}$.

4. Martorell R. The nature of child malnutrition and its long-term implications. Food Nutr Bull. 1999 Sep;20(3):288-92. doi: 10.1177/15648265 9902000304.

5. Peirson L, Fitzpatrick-Lewis D, Morrison K, Ciliska D, Kenny M, Usman Ali $\mathrm{M}$, et al. Prevention of overweight and obesity in children and youth a systematic review and meta-analysis. Can Med Assoc J. 2015 Jan 3(1):23-33. PMID: 25844367. doi: 10.9778/cmajo.20140053.
6. Calle EE, Kaaks R. Overweight, obesity and cancer: epidemiological evidence and proposed mechanisms. Nat Rev Cancer. 2004 Aug;4(8): 579-91. PMID: 15286738. doi: 10.1038/nrc1408.

7. Daniels SR, Arnett DK, Eckel RH, Gidding SS, Hayman LL, Kumanyika S, et al. Overweight in children and adolescents: pathophysiology, consequences, prevention, and treatment. Circulation. 2005 Apr;111(15): 1999-2012. PMID: 15837955. doi: 10.1161/01.CIR.0000161369.71722.10.

8. Dietz WH. Overweight in childhood and adolescence. N Engl J Med. 2004 Feb;350(9):855-7. PMID: 14985480. doi: 10.1056/NEJMp048008.

9. Benton D. Micronutrient status, cognition and behavioral problems in childhood. Eur J Nutr. 2008 Aug;47(Suppl. 3):38-50. PMID: 18683028. doi: 10.1007/s00394-008-3004-9.

10. Pollitt E, Golub M, Gorman K, Grantham-McGregor S, Levitsky D, Schurch B, et al. A reconceptualization of the effects of undernutrition on children's biological, psychosocial, and behavioral development and commentaries. Soc Policy Rep. 1996 Jan;10(5):1-32. doi: 10.1002/j.23793988.1996.tb00003.x.

11. Rao TSS, Asha MR, Ramesh BN, Rao KSJ. Understanding nutrition, depression and mental illnesses. Indian J Psychiatry. 2008 Apr;50(2): 77-82. PMID: 19742217. doi: 10.4103/0019-5545.42391.

12. Fung C, Kuhle S, Lu C, Purcell M, Schwartz M, Storey K, et al. From "best practice" to "next practice": the effectiveness of school-based health promotion in improving healthy eating and physical activity and preventing childhood obesity. Int J Behav Nutr Phys Act. 2012 Mar;9(1):27. PMID: 22413778. doi: 10.1186/1479-5868-9-27.

13. He M, Beynon C, Sangster Bouck M, St Onge R, Stewart S, Khoshaba L, et al. Impact evaluation of the Northern Fruit and Vegetable Pilot programme-a cluster-randomised controlled trial. Public Health Nutr. 2009 Nov;12(11):2199-208. PMID: 19476675. doi: 10.1017/S1368 980009005801

14. Drapeau V, Savard M, Gallant A, Nadeau L, Gagnon J. The effectiveness of a school-based nutrition intervention on children's fruit, vegetables, and dairy product intake. J Sch Health. 2016 May;86(5):353-62. PMID: 27040473. doi: 10.1111/josh.12385.

15. Dalen JE, Devries S. Diets to prevent coronary heart disease 1957-2013: what have we learned? Am J Med. 2014 May;127(5):364-9. PMID: 24384466. doi: 10.1016/j.amimed.2013.12.014.

16. WHO. Diet, nutrition and the prevention of chronic diseases. World Health Organization Technical Report Series No. 916; Geneva: WHO, 2002.

17. Schardt C, Adams MB, Owens T, Keitz S, Fontelo P. Utilization of the PICO framework to improve searching PubMed for clinical questions. BMC Med Inform Decis Mak. 2007 Jun;7:16. PMID: 17573961. doi: 10.1186/ 1472-6947-7-16.

18. Miller LMS, Cassady DL. The effects of nutrition knowledge on food label use. A review of the literature. Appetite. 2015 Sep;92:207-16. PMID: 26025086. doi: 10.1016/j.appet.2015.05.029.

19. Baranowski T, Cullen KW, Baranowski J. Psychosocial correlates of dietary intake: advancing dietary intervention. Annu Rev Nutr. 1999 Feb;19(1):17-40. PMID: 10448515. doi: 10.1146/annurev.nutr.19.1.17.

20. Department of Education. Food and nutrition policy for New Brunswick schools. No. 14-700-005; Fredericton: Government of New Brunswick, 1991.

21. Moher D, Liberati A, Tetzlaff J, Altman DG. Preferred reporting items for systematic reviews and meta-analyses: the PRISMA statement. PLoS Med. 2009 Jul;6(7):e1000097. PMID: 19621072. doi: 10.1371/journal.pmed. 1000097.

22. Zingg W, Castro-Sanchez E, Secci FV, Edwards R, Drumright LN, Sevdalis N, et al. Innovative tools for quality assessment: integrated quality criteria for review of multiple study designs (ICROMS). Public Health. 2016 Apr;133:19-37. PMID: 26704633. doi: 10.1016/j.puhe.2015.10.012.

23. Gates M, Hanning RM, Gates A, Isogai A, Tsuji LJS, Metatawabin J. A pilot comprehensive school nutrition program improves knowledge and intentions for intake of milk and milk alternatives among youth in a remote first nation. J Nutr Educ Behav. 2013 Sep;45(5):455-9. PMID: 23414784. doi: 10.1016/j.jneb.2012.12.002.

24. Veugelers PJ, Fitzgerald AL. Effectiveness of school programs in preventing childhood obesity: a multilevel comparison. Am J Public Health. 2005 Mar;95(3):432-5. PMID: 15727972. doi: 10.2105/AJPH.2004.045898.

25. Saksvig BI, Gittelsohn J, Harris SB, Hanley AJG, Valente TW, Zinman B. A pilot school-based healthy eating and physical activity intervention improves diet, food knowledge, and self-efficacy for Native Canadian children. J Nutr. 2005 Oct;135(10):2392-8. PMID: 16177202. doi: 10.1093/jn/ 135.10.2392. 
26. Bisset SL, Potvin L, Daniel M, Paquette M. Assessing the impact of the primary school-based nutrition intervention Petits cuistots-parents en réseaux. Can J Public Health. 2008 Mar;99(2):107-13. PMID: 18457283. doi: $10.17269 /$ cjph.99.1611.

27. Hanbazaza MA, Triador L, Ball GDC, Farmer A. The impact of school gardening on Cree children's knowledge and attitudes toward vegetables and fruit. Can J Diet Pract Res. 2015 Sep;76(3):133-9. PMID: 26280793. doi: 10.3148/cjdpr-2015-007.

28. Day M, Strange K, McKay H, Naylor P. Action schools! BC-healthy eating: effects of a whole-school model to modifying eating behaviours of elementary school children. Can J Public Health. 2008 Jul;99(4):328-31. PMID: 18767281.

29. Traidor L, Farmer A, Maximova K, Willows N, Kootenay J. A school gardening and healthy snack program increased Aboriginal First Nations children's preferences toward vegetables and fruit. J Nutr Educ Behav. 2015 Mar;47(2):176-80. PMID: 25439764. doi: 10.1016/j.jneb. 2014.09.002.

30. He M, Beynon CE, Gritke JL, Henderson ML, Kurtz JM, Sangster Bouck $M$, et al. Children's perceptions of the Northern Fruit and Vegetable Program in Ontario, Canada. J Nutr Educ Behav. 2012 Nov;44(6):592-6. PMID: 21724470. doi: 10.1016/j.jneb.2010.09.014.

31. Gates M, Hanning RM, Gates A, McCarthy DD, Tsuji LJS. Assessing the impact of pilot school snack programs on milk and alternatives intake in 2 remote First Nation communities in Northern Ontario, Canada. J Sch Health. 2013 Feb;83(2):69-76. PMID: 23331265. doi: 10.1111/josh.12000.
32. Sahay TB, Ashbury FD, Roberts M, Rootman I. Effective components for nutrition interventions: a review and application of the literature. Health Promot Pract. 2006 Oct;7(4):418-27. PMID: 16928989. doi: 10.1177/152 4839905278626.

33. Aloia CR, Shockey TA, Nahar VK, Knight KB. Pertinence of the recent school-based nutrition interventions targeting fruit and vegetable consumption in the United States: a systematic review. Health Promot Perspect. 2016 Mar;6(1):1-9. PMID: 27123430. doi: 10.15171/hpp. 2016.01.

34. Morris JL, Zidenberg-Cherr S. Garden-enhanced nutrition curriculum improves fourth-grade school children's knowledge of nutrition and preferences for some vegetables. J Am Diet Assoc. 2002 Jan;102(1):91-3. PMID: 11794509. doi: 10.1016/S0002-8223(02)90027-1.

35. Reinaerts E, de Nooijer J, Candel M, de Vries N. Increasing children's fruit and vegetable consumption: distribution or a multicomponent programme? Public Health Nutr. 2007 Sep;10(9):939-47. PMID: 17381944. doi: $10.1017 /$ S1368980007665495.

36. Knai C, Pomerleau J, Lock K, McKee M. Getting children to eat more fruit and vegetables: a systematic review. Prev Med. 2006 Feb;42:85-95. PMID: 16375956. doi: 10.1016/j.ypmed.2005.11.012.

37. Godin KM, Kirkpatrick SI, Hanning RM, Stapleton J, Leatherdale SC. Examining guidelines for school-based breakfast programs in Canada: a systematic review of the grey literature. Can J Diet Pract Res. 2017 Jun; 78:92-100. PMID: 28145767. doi: 10.3148/cjdpr-2016-037. 